\title{
THE SPITZER LAW FOR $\psi$-MIXING RANDOM VARIABLES
}

\section{Xiangdong LiU And XiaOJIE Jin}

Abstract. The Spitzer law is obtained for the maximun partial sums of the identically distributed $\psi$-mixing random variables without any conditions on mixing rate, and another proof of the classical Kolmogorov strong law of large numbers is also given for them.

Mathematics subject classification (2010): 60F15.

Keywords and phrases: Spitzer law, strong law of large number, $\psi$-mixing.

\section{REFERENCES}

[1] L. E. Baum, M. KatZ, Convergence rate in the law of large numbers, Trans. Amer. Math. Soc. 120 (1965), 108-123.

[2] J. R. Blum, D. L. HANSON, L. H. KoOpmans, On the strong law of large numbers for a class of stochastic processes, Z. Wahrsch. Verw. Gebiete 2 (1963), 1-11.

[3] P. Chen, T.-C. HU, AND A. Volodin, A note on the rate of complete convergence for maximum of partial sums for moving average processes in Rademacher type Banach spaces, Lobachevskii J. Math. 21 (2006), 45-55.

[4] P. Hsu, H. Robbins, Complete convergence and the law of large numbers, Proc. Natl. Acad. Sci. USA, 33 (1947), 25-31.

[5] D. Hu, P. Chen, H. S. Sung, Strong laws for weighted sums of $\psi$-mixing random variables and applications in errors-in-variables regression models, Test 26 (2017), 600-617.

[6] Z. Y. Lin, C. Y. Lu, Limit Theory for Mixing Random Variables, Kluwer Academic Publishers/Science Press, Dordrecht/Beijing, 1997.

[7] F. SPITZER, A combinatorial lemma and its application to probability theory, Tran. Amer. Math. Soc. 82 (1956), 323-339.

[8] Q. ShaO, A moment inequality and its application, Acta Math. Sin. 31 (1988), 736-747 (in Chinese).

[9] W. F. Stout, Almost Sure Convergence, Academic Press, New York, 1974. 